\title{
Photosynthetic traits and biochemical responses in strawberry (Fragaria $\times$ ananassa Duch.) leaves supplemented with LED lights
}

\author{
G. LAURIA ${ }^{*}$, , E. LO PICCOLO ${ }^{*}$, , E. PELLEGRINI*, E. BELLINI ${ }^{* *}$, T. GIORDANI ${ }^{*}$, L. GUIDI $^{*,+}$, \\ G. LORENZINI*, F. MALORGIO*, R. MASSAI*, C. NALI*, L. PAOLI**, D. REMORINI*, \\ L. SANITA' DI TOPPI ${ }^{* *}$, P. VERNIERI ${ }^{* *}$, and M. LANDI ${ }^{*}$
}

Department of Agriculture, Food and Environment, University of Pisa, 56124 Pisa, Italy*

Department of Biology, University of Pisa, via Ghini 13, 56126 Pisa, Italy ${ }^{* *}$

\begin{abstract}
Selected light wavebands promote plant development and/or the biosynthesis of targeted metabolites. This work offers new insights on the effects of red (R), green $(\mathrm{G})$, blue (B), and white (W - R:G:B; 1:1:1) LED light supplementation on physiochemical traits of strawberry leaves. Gas exchange and chlorophyll fluorescence parameters, photosynthetic pigments, and superoxide anion $\left(\mathrm{O}_{2}^{-}\right)$content were analysed in plants grown for 1 (T1) and 17 (T17) d with light supplementations. At T1, light supplementations resulted in the enhancement of the de-epoxidation state of xanthophylls and nonphotochemical quenching, but no changes were observed in maximal photosynthetic rate $\left(P_{\text {Nmax }}\right)$, irrespective of light spectra. At T17, xanthophyll contents remained higher only in R-supplemented plants. Overall, W light resulted in higher photosynthesis, whilst R and B light depressed $P_{\mathrm{Nmax}}$ values and promoted ${ }^{\circ} \mathrm{O}_{2}{ }^{-}$formation at T17. G light did not induce variations in photosynthetic traits nor induced oxidative stress at both T1 and T17.
\end{abstract}

Keywords: chlorophyll $a$ fluorescence; gas exchange; mesophyll conductance; oxidative stress; superoxide anion; xanthophyll.

\section{Introduction}

Artificial light supplementation promotes specific reactions of photosynthesis and/or increases plant performance, especially in protected and indoor environments, in which plants have to compete for light harvesting (Folta and Childers 2008, Cocetta et al. 2017). In recent years, light-emitting diodes (LEDs) have been proficiently used

\section{Highlights}

- One-day light supplementation promotes nonphotochemical quenching in strawberry

- W light promotes photosynthesis, while R and B depresses it after $17 \mathrm{~d}$ of exposure

- G light does not alter xanthophyll contents and photosynthetic traits
Received 8 June 2021

Accepted 12 October 2021

Published online 26 October 2021

${ }^{+}$Corresponding author

phone: +39050 2216613

e-mail: lucia.guidi@unipi.it

Abbreviations: B - blue light supplementation; Car - carotenoids; Chl - chlorophyll; $C_{\mathrm{i}}-$ intercellular $\mathrm{CO}_{2}$ concentration; DEPS de-epoxidation state of xanthophyll cycle pigments; ETR - electron transport rate; flav - flavonoids; FM - fresh mass; $\mathrm{F}_{\mathrm{v}} / \mathrm{F}_{\mathrm{m}}-$ maximum quantum yield of PSII; G - green light supplementation; $g_{\mathrm{m}}-$ mesophyll conductance; $g_{\mathrm{s}}$ - stomatal conductance; $J_{1300}-$ electron transport obtained at saturating light; LED - light emitting diode; NBI - nitrogen balance index; NS - control; $P_{\mathrm{N}}$ - net photosynthetic rate; $P_{\mathrm{Nmax}}-$ light-saturated net photosynthetic rate; $\mathrm{q}_{\mathrm{N}}-$ nonphotochemical quenching coefficient; $\mathrm{q}_{\mathrm{P}}-$ photochemical quenching coefficient; R - red light supplementation; $R_{\mathrm{L}}$ - mitochondrial respiration in the light; ROS - reactive oxygen species; $\mathrm{SE}$ - standard error; T1/T17 - 1/17 d of light supplementation; TPU - triose phosphate-utilization rate; VAZ - total amount of xanthophyll cycle components; $V_{\text {cmax }}$ - maximum rate of carboxylation of Rubisco; W - white (R:G:B; 1:1:1) light supplementation; XTT - 3'-(1-[phenylaminocarbonyl]-3,4-tetrazolium)-bis(4-methoxy-6-nitro) benzene-sulfonic acid hydrate; $\alpha$-toc - $\alpha$-tocopherol; $\Gamma^{*}-\mathrm{CO}_{2}$ compensation point in absence of respiration; $\Phi_{\mathrm{NPQ}}-$ quantum yield of nonphotochemical quenching; $\Phi_{\mathrm{PSII}}-$ operational quantum yield of PSII photochemistry.

Acknowledgments: This study was performed in the framework of the PRA 2020-2021 project 'Fragoal' financed by the University of Pisa.

$\dagger^{\dagger}$ Authors contributed equally.

Conflict of interest: The authors declare that they have no conflict of interest. 
as light sources in greenhouse cultivation and they have a great commercial appeal due to their benefits for both research and productive purposes (Bantis et al. 2018). LED-based light sources have numerous advantages over traditional light sources: (1) LED allows control over emission spectrum (Bourget 2008, Morrow 2008), (2) they are more energy-efficient (Singh et al. 2015); (3) radiate very little heat so can be placed close to the plants thereby increasing the irradiances over the leaf lamina; (4) their compactness reduces shadowing problems (Cocetta et al. 2017). LEDs are often used to provide supplemental narrow-band light, which may exert specific and targeted effects on morphoanatomical traits, photosynthesis, as well as secondary metabolism, in particular with 'colorspecific' effects (Landi et al. 2020), and also activate plant defence against pathogens (Ballaré 2014). Selected LED lights are used in a controlled environment, mainly in growth chambers, whereas only a little research has been conducted on the use of specific LED wavebands in greenhouse-enrichment experiments (Bantis et al. 2018).

Blue LED light was reported to increase net photosynthetic rate $\left(P_{\mathrm{N}}\right)$ and stomatal conductance $\left(g_{\mathrm{s}}\right)$ under high-light conditions (Li et al. 2017) as well as decrease electron transport rate (ETR) and PSII quantum yield $\left(\Phi_{\text {PSII }}\right)$ values associated with an increase in heat dissipation from PSII (NPQ and $\Phi_{\mathrm{NPQ}}$ ) (Ouzounis et al. 2015). Conversely, red light supplementation was more effective in increasing $P_{\mathrm{N}}$ especially under low-light conditions (Li et al. 2017). Green light is usually neglected due to the misconception that plants do not absorb the green region of the spectrum and only reflect those wavelengths (Smith et al. 2017). Differently, some studies underlined that green light can be absorbed by chlorophyll (Chl) $b$ in the deeper canopy layers (Sun et al. 1998) and by carotenoids (Govindjee 1982a,b); furthermore, green light can act as a shade signal (Smith et al. 2017) and increase water-use efficiency within the canopy layers (Frechilla et al. 2000, Talbott et al. 2002, 2006). Green light also regulates some essential processes of the plant, from seed germination to flowering (Golovatskaya and Karnachuk 2015). Given these assumptions, Smith et al. (2017) suggested the use of green LED light supplementation for greenhouse production.

The use of selected LED colours exerts a plethora of reactions, in most cases species-specific and wavebanddependent on the secondary metabolism of plants (Landi et al. 2020). Overall, the supplementation of LED lights (independently to the emission spectra) generally promotes the increase of Chl content in some leafy greens (Matysiak and Kowalski 2019), whereas, in terms of flavonoid metabolism, blue LED light usually stimulates the activation of anthocyanin pattern (Mizuno et al. 2011, Olle and Virsile 2013). In controlled environments, red light also stimulated the biosynthesis of other polyphenols ( $\mathrm{Li}$ and Kubota 2009) as well as glucosinolates (Lefsrud et al. 2008). In preharvest, the application of red LED increased the antioxidant capacity in lettuce leaves (Zukauskas et al. 2011) and reduced the nitrate content in lettuce and onion (Samuolienè et al. 2009). Moreover, red light increased shoot fresh biomass in Eruca sativa L. and stimulated leaf elongation of Valerianella locusta and garden rocket plants (Matysiak and Kowalski 2019).

In other cases, blue LED light promotes the accumulation of other secondary metabolites, including flavonols (Matysiak and Kowalski 2019), phenolic acids, flavonoids sensu lato, and pigments in red leaf lettuce (Ouzounis et al. 2015), chlorophylls in cabbage seedlings (Mizuno et al. 2011), and anthocyanins and carotenoids in baby leaf lettuce (Li and Kubota 2009). Blue LED light also promoted petiole elongation in cabbage seedlings (Mizuno et al. 2011).

Because of the modulatory effect on secondary metabolism, specific narrow-band light supplementation may also promote fruit quality (Landi et al. 2020) as well as plant defence reactions. For example, red LEDs significantly reduced the incidence of powdery mildew (Sphaerotheca fuliginea) in cucumber plants (Wang et al. 2010) and both blue (Kim et al. 2013) and red (Xu et al. 2017) LED light inhibited the development of grey mould disease (Botrytis cinerea) in tomato plants due to the stimulation of plantdefensive compounds.

As the topic is a warrant further investigation, for the present experiment, we selected strawberry (Fragaria $\times$ ananassa) which is a perennial herbaceous species belonging to Rosaceae family, widely cultivated for its fruits, and economically relevant for indoor cultivation. For its small size and short life cycle, it can be considered a good model plant. Despite several studies that have been carried out on this species, scarce information is available on the possible effect of light supplementation in greenhouse-grown plants. Previous experiments conducted with the strawberry highlighted that supplementation of plants with composite LED lighting systems enhanced photosynthetic traits (Hidaka et al. 2013). Red-LED supplementation resulted effective in the promotion of the early flowering and fruiting stage (Jamal Uddin et al. 2018). Blue light resulted effective in increasing leaflets length (Choi et al. 2015), plant height, leaf number and area (Jamal Uddin et al. 2018), and strawberry fruit production (Choi et al. 2015). To date, no data are available for the green light.

The establishment of a positive effect by supplementation of some LED colours (red, green, and blue) on fruit quality and plant resistance against some pathogens (e.g., B. cinerea) should be tested. However, it is essential to evaluate the effect of different LED colour supplementation in leaves, this in order to prevent damages to the photosynthetic apparatus as well as avoid improper development of the plants. Indeed, specific red-, green-, blue-light-triggered physiobiochemical changes in leaves could nullify the use of such wavebands to promote fruit quality and pathogen resistance response.

Assuming that little and not consistent information is available about the effect of LED light supplementation in strawberry plants, the present research aimed to investigate the effects of light provided by red (R), green (G), and blue (B) LEDs, and white (W) light supplementation (R:G:B; 1:1:1) on physiological and biochemical features of strawberry leaves. The present work aims to select the best light supplementation to stimulate strawberry 
photosynthetic performances. Future research will evaluate the impact of those LED supplementations in fruit quality and disease resistance in indoor-grown strawberry plants.

\section{Materials and methods}

Plant material and growth conditions: Twenty-day-old commercial strawberry plants (Fragaria $\times$ ananassa) were transplanted on 30 June 2020 into a glasshouse located at the Department of Agriculture, Food and Environment (DiSAAA-a), University of Pisa $\left(43.704672^{\circ} \mathrm{N}\right.$, $\left.10.427292^{\circ} \mathrm{E}\right)$. Each plant was transplanted in a $3-\mathrm{L}$ pot filled with sandy soil-peat mixture (60:40; v:v). Plants were irrigated with deionized water during the first week after transplanting and afterwards with a nutrient solution containing the following nutrient concentrations: $14.0 \mathrm{mM}$ $\mathrm{NO}_{3}{ }^{-}, 1.0 \mathrm{mM} \mathrm{NH}_{4}^{+}, 1.0 \mathrm{mM} \mathrm{P}, 6.03 \mathrm{mM} \mathrm{K}^{+}, 3.14 \mathrm{mM}$ $\mathrm{Ca}^{2+}, 1.7 \mathrm{mM} \mathrm{Mg}{ }^{2+}, 5.22 \mathrm{mM} \mathrm{Na}$, $2.39 \mathrm{mM} \mathrm{SO}_{4}{ }^{2-}$, $15.0 \mu \mathrm{M} \mathrm{Fe}^{2+}, 20.00 \mu \mathrm{M} \mathrm{BO}_{3}^{-}, 1.0 \mu \mathrm{M} \mathrm{Cu}^{2+}, 5.0 \mu \mathrm{M} \mathrm{Zn}^{2+}$, $10.0 \mu \mathrm{M} \mathrm{Mn}^{2+}, 1.0 \mu \mathrm{M} \mathrm{Mo}^{3+}$. Electrical conductivity (EC) was $1.9 \mathrm{mS} \mathrm{cm}$; $\mathrm{pH}$ values were adjusted to 5.5 with diluted sulfuric acid.

Experiments took place from the end of June to the end of July and climatic parameters were continuously monitored by a weather station placed inside the glasshouse. The minimum and average air temperatures were 24 and $30^{\circ} \mathrm{C}$, respectively; the maximum temperature reached up to $32-36^{\circ} \mathrm{C}$ in sunny hours. In total, 20 plants were used (five replicates per treatment). Control (NS) was exposed to ambient light only, while for other treatments plants were exposed to ambient light with supplemental LED lighting. For LED illumination, four lamps $(1,200 \times 68 \times$ $36 \mathrm{~mm}$ ) purchased from Ambra Elettronica s.r.l. (Bolzano Vicentino, VI, Italy) were used: red (R; peak $660 \mathrm{~nm})$, blue (B; $450 \mathrm{~nm})$, green $(\mathrm{G} ; 530 \mathrm{~nm})$, and white (W - R:G:B, $1: 1: 1$ ), radiating $250 \mu \mathrm{mol}$ (photon) $\mathrm{m}^{-2} \mathrm{~s}^{-1}$ of light for five hours per day (from 11:00 to 16:00 h). Light spectra of each lamp were reported in Fig. 1. Analysis was conducted on leaves continuously exposed to the treatments from the

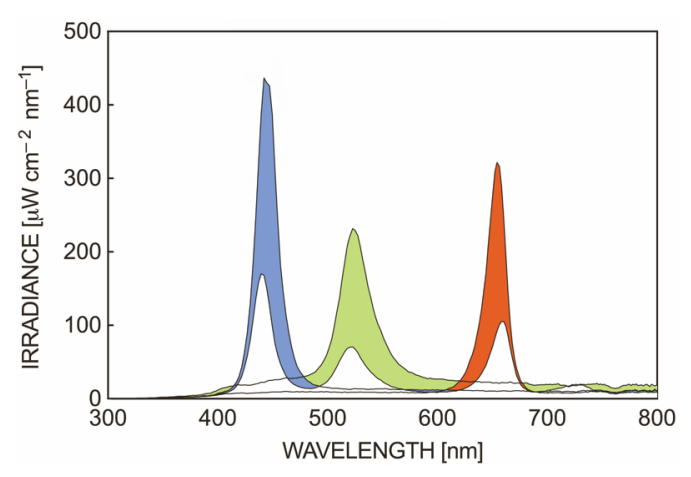

Fig. 1. Spectrum of LED supplemental light sources used in the experiment: blue LED light (peak wavelength at $450 \mathrm{~nm}$ ); green LED light (peak wavelength at $530 \mathrm{~nm}$ ); red LED light (peak wavelength at $660 \mathrm{~nm}$ ); white LED light (peak wavelength at 450,530 , and $660 \mathrm{~nm}$ ). The spectral distributions were measured with a handheld spectroradiometer (SpectraPen, Photon Systems Instruments, Drásov, Czech Republic). beginning of the trials; flower buds were removed for the maintenance of homogenous conditions. Measurements were taken the day after $24 \mathrm{~h}$ of light supplementation (T1) and after $17 \mathrm{~d}$ (T17).

Two kinds of analysis were conducted: nondestructive physiological investigations (encompassing gas exchange, Chl $a$ fluorescence, and DUALEX ${ }^{\circledR}$ measurements) and destructive biochemical analyses (evaluation of chlorophylls, carotenoids, tocopherol content, and oxidative stress markers). For destructive analyses, samples were firstly collected into liquid nitrogen, cryogenically ground, and stored at $-80^{\circ} \mathrm{C}$.

Gas exchange and $\mathrm{Chl} \boldsymbol{a}$ fluorescence parameters were measured $(n=3)$ using a portable infrared gas analyser $L I-6400$ system ( $\mathrm{Li}$-Cor, Lincoln, NE, USA) and PAM-2000 fluorometer (Walz, Effeltrich, Germany), respectively.

Gas-exchange measurements were conducted on randomly selected fully expanded leaves from 10:00 to 14:00 h at light of saturating intensity of $1,300 \mu \mathrm{mol}$ (photon) $\mathrm{m}^{-2} \mathrm{~s}^{-1}$. Inside the leaf chamber, the $\mathrm{CO}_{2}$ concentration was set to $400 \mu \mathrm{mol}\left(\mathrm{CO}_{2}\right) \mathrm{mol}^{-1}$ by using the $\mathrm{CO}_{2}$ mixer, the leaf temperature was blocked at $\sim 30^{\circ} \mathrm{C}$, relative humidity was maintained at $\sim 50 \%$, and the flow rate was $500 \mu \mathrm{mol} \mathrm{s}{ }^{-1}$. Once the steady state was reached, light-saturated net photosynthetic rate $\left(P_{\mathrm{Nmax}}\right)$, stomatal conductance $\left(g_{\mathrm{s}}\right)$, and intercellular $\mathrm{CO}_{2}$ concentration $\left(C_{\mathrm{i}}\right)$ were recorded. Immediately after $P_{\mathrm{N}} / C_{\mathrm{i}}$ response curves were conducted on the same leaves. $P_{\mathrm{N}} / C_{\mathrm{i}}$ curves were obtained by adjusting the $\mathrm{CO}_{2}$ concentration inside the leaf chamber to $400,200,150,50,400,600,800$; 1,$000 ; 1,200 ; 1,500 \mu \operatorname{mol}\left(\mathrm{CO}_{2}\right) \mathrm{mol}^{-1}$. The maximum rate of carboxylation $\left(V_{\mathrm{cmax}}\right)$, electron transport obtained at saturating light of $1,300 \mu \mathrm{mol}$ (photon) $\mathrm{m}^{-2} \mathrm{~s}^{-1}\left(J_{1300}\right)$, and triose phosphate-utilization rate (TPU) were estimated according to Long and Bernacchi (2003), based on the model of Farquhar et al. (1980). Mitochondrial respiration in the light $\left(R_{\mathrm{L}}\right)$ was considered as half of the mitochondrial respiration (measured during the dark; Gago et al. 2013), and the $\mathrm{CO}_{2}$-compensation point in absence of respiration $\left(\Gamma^{*}\right)$ was assumed to be 44.04 at $30^{\circ} \mathrm{C}$ (Bernacchi et al. 2002). Mesophyll conductance $\left(g_{\mathrm{m}}\right)$ was estimated using the variable J method (Harley et al. 1992), through the combination of gas exchange and $\mathrm{Chl} a$ fluorescence analysis.

Chl $a$ fluorescence parameters were measured from 10:00 to 14:00 $\mathrm{h}$ in leaves homogeneous to those used for gas exchange. After 30 min of dark adaptation, operational quantum yield $\left(\Phi_{\text {PSII }}\right)$, nonphotochemical $\left(\mathrm{q}_{\mathrm{N}}\right)$ and photochemical quenching coefficient $\left(\mathrm{q}_{\mathrm{P}}\right)$, the maximum quantum yield of PSII $\left(\mathrm{F}_{\mathrm{v}} / \mathrm{F}_{\mathrm{m}}\right)$, and electron transport rate (ETR) of PSII were measured. Analysis was performed on the leaf central section of the three leaflets terminal leaf, avoiding midrib.

Chl, flavonoid indexes, and nitrogen balance index (NBI) analysis: Investigations were performed using a $D U A L E X^{\circledR}$ (Force-A, Orsay, France). NBI was considered a good estimator of leaf nitrogen content. Data 
were collected on mature leaves from three samples per treatment. Each sample was analysed thrice on the abaxial and adaxial leaf face.

Chl, carotenoids, and $\alpha$-tocopherol content determination: According to García-Plazaola and Esteban (2016), samples between $0.03-0.05 \mathrm{~g}$ of fresh matter (FM) were added to $100 \%$ HPLC-grade methanol $(1: 10, \mathrm{w}: \mathrm{v})$ and stored at $4^{\circ} \mathrm{C}$ in the dark for $12 \mathrm{~h}$. Later, samples were centrifuged at $12,000 \times g$ for $10 \mathrm{~min}$ at $4^{\circ} \mathrm{C}$, and supernatants were filtered with $0.22 \mu \mathrm{m}$ Minisart ${ }^{\circledR}$ SRT 15 filters. For pigments determination, an UltraHPLC Dionex UltiMate 3000 system was used, equipped with an UltiMate autosampler, a Dionex TCC-100 column oven, and a Dionex UVD 170 U UV-Vis detector (Thermo Scientific, Waltham, MA, USA). Each running last for $30 \mathrm{~min}$ with a $1 \mathrm{~mL} \mathrm{~min}^{-1}$ flow. Acetonitrile/methanol (75:25, v:v) was used at $100 \%$ for the first $12 \mathrm{~min}$ followed by 1.5 -min linear gradient to $100 \%$ solved B methanol/ethyl acetate (68:32, v:v), $15 \mathrm{~min}$ with $100 \%$ solvent $\mathrm{B}$, followed by 2 -min linear gradient to $100 \%$ solvent A to elute respectively xanthophylls on one hand and chlorophylls and $\beta$-carotene on the other. A Dionex ${ }^{\mathrm{TM}}$ C18 Acclaim 120, Thermo Scientific ${ }^{\mathrm{TM}}$ column $(5 \mu \mathrm{m}$ particle size, $4.6 \mathrm{~mm}$ internal diameter $\times$ $150 \mathrm{~mm}$ length) was used, by setting the column oven at $30^{\circ} \mathrm{C}$. Two specific wavelengths were controlled with a UV-Vis detector: $295 \mathrm{~nm}$ for $\alpha$-tocopherol determination and $445 \mathrm{~nm}$ for photosynthetic pigments. Results were compared with standards obtained as $1 \mathrm{mg} \mathrm{mL}^{1}$ solution in pure HPLC methanol and then filtrated with $0.22 \mu \mathrm{m}$ filters, while calibration solutions were obtained through dilution. Chl, carotenoids, and $\alpha$-tocopherol quantitative determination data were processed with Chromeleon Chromatography Management System software, version 7.2.10-2019 (Thermo Scientific). Chl $a / b$ ratio, total Chl content [Chl $(a+b)]$, total amount of xanthophyll cycle components (VAZ: violaxanthin + antheraxanthin + zeaxanthin), the de-epoxidation state of xanthophyll cycle pigments (DEPS) calculated as (antheraxanthin + zeaxanthin $) /($ violaxanthin + antheraxanthin + zeaxanthin $)$, and $\mathrm{Car} / \mathrm{Chl}$ ratio calculated as $(\beta$-carotene + lutein + violaxanthin + antheraxanthin + zeaxanthin $) /(\mathrm{Chl} a+b)$ were also determined.

Superoxide anion determination: The ${ }^{\circ} \mathrm{O}_{2}{ }^{-}$content was determined using the tetrazolium salt dye, 3'-(1-[phenylamino-carbonyl]-3,4-tetra-zolium)-bis(4-methoxy6-nitro) benzene-sulfonic acid hydrate (XTT) which can be reduced by ${ }^{\circ} \mathrm{O}_{2}^{-}$to a soluble formazan that can be readily quantified in solution (Sutherland and Learmonth 1997). Samples $[0.10 \mathrm{~g}(\mathrm{FM})]$ were extracted with $1 \mathrm{~mL}$ of $50 \mathrm{mM}$ $(\mathrm{pH} 7.8) \quad \mathrm{K}_{3} \mathrm{PO}_{4}$ buffer solution. After centrifugation $\left(10,000 \times g\right.$ for $15 \mathrm{~min}$ at $\left.4^{\circ} \mathrm{C}\right)$ supernatants were selected. Solution obtained as $287 \mu \mathrm{L}$ buffer $+3 \mu \mathrm{L}$ XTT $+10 \mu \mathrm{L}$ extract, filled each well. XTT reduction was evaluated every $30 \mathrm{~min}$ for $180 \mathrm{~min}$ total, measuring absorbance at $470 \mathrm{~nm}$. Data obtained at $60 \mathrm{~min}$ were selected. ${ }^{\circ} \mathrm{O}_{2}^{-}$ concentration was determined using molar extinction coefficient $(\varepsilon) 21.6 \mathrm{mM}^{-1} \mathrm{~cm}^{-1}$ (Able et al. 1998) and expressed as nmol $\mathrm{g}^{-1}(\mathrm{FM})$.
Statistical analysis: Each data represents the mean value of three independent replicates $( \pm S E)$, except for Dualex $^{\mathbb{R}}$ data whose mean is derived from nine replicates. Homoscedasticity of data was evaluated by Bartlett's test. All data were subjected to one-way analysis of variance ( $A N O V A)$ considering light treatment as the only source of variability. Significant differences between light treatments were determined by LSD post-hoc test $(P \leq 0.05)$.

\section{Results}

Gas-exchange analysis: At T1, no significant differences between treatments were found for $P_{\mathrm{Nmax}}$, whereas at T17, W-supplemented plants showed the highest values of $P_{\text {Nmax }}$ $\left[17.15 \pm 0.25 \mu \mathrm{mol}\left(\mathrm{CO}_{2}\right) \mathrm{m}^{-2} \mathrm{~s}^{-1}\right]$, followed by control (NS) and G. At the same time, in the B- and R-supplemented leaves the lowest values of $P_{\mathrm{N} \max }$ were recorded [12.37 \pm 0.57 and $12.53 \pm 0.95 \mu \mathrm{mol}\left(\mathrm{CO}_{2}\right) \mathrm{m}^{-2} \mathrm{~s}^{-1}$, respectively; Fig. $2 A$ ]. At T1, values of $g_{\text {s }}$ were similar in leaves of NS plants and those subjected to R and G treatments; plants supplemented with $\mathrm{W}$ light showed higher values than that of the aforementioned treatments, whereas $g_{\mathrm{s}}$ was significantly depressed by B light (Fig. 2B). At T17, no significant differences were observed between $B, R, G$ $v s$. NS and only $\mathrm{W}$ light induced an increase of stomatal conductance compared to NS, B, and G $(+15.2,+22.7$, and $+24.2 \%$, respectively; Fig. $2 B$ ). At T1, plants grown with $\mathrm{W}$ light supplementation had higher values of $C_{\mathrm{i}}$ for NS, B, and G treatments, whereas only B-enriched plants showed the lowest values among all the treatments $\left[223.00 \pm 1.00 \mu \mathrm{mol}\left(\mathrm{CO}_{2}\right) \mathrm{mol}^{-1}\right.$; Fig. 2C]. At T17, $\mathrm{B}$ - and R-supplemented plants resulted in the highest values of $C_{\mathrm{i}}$ values for NS, W, and $\mathrm{G}$ light (Fig. 2C). At $\mathrm{T} 1, \mathrm{~B}$ resulted in increased $g_{\mathrm{m}}$ levels $(+21.1 \%$ compared with NS), whereas no significant differences were recorded between the other light treatments. At T17, NS plants and those enriched with $G$ light shared similar values of $g_{\mathrm{m}}$, whilst B and $\mathrm{R}$ light induced a decline of this parameter. W resulted in higher values of $g_{\mathrm{m}}$ compared to other light treatments (Fig. 2D). $V_{\text {cmax }}$ increased under $\mathrm{W}$ and $\mathrm{B}$ at $\mathrm{T} 1$ compared to NS $(+16.9$ and $+30.1 \%$, respectively), reaching the highest values under $\mathrm{B}$ treatment $\left[100.60 \pm 0.35 \mu \mathrm{mol}\left(\mathrm{CO}_{2}\right) \mathrm{m}^{-2} \mathrm{~s}^{-1}\right.$; Fig. 2E]. After $17 \mathrm{~d}$, values of $V_{\text {cmax }}$ were similar in $\mathrm{NS}, \mathrm{W}$, and $\mathrm{G}$, while $\mathrm{B}$ and $\mathrm{R}$ resulted in lower carboxylation rates $(-25.5$ and $-34.2 \%$ compared with NS, respectively; Fig. $2 E$ ). $J_{1300}$ and TPU values had a similar trend: at T1, no significant differences emerged between treatments, whereas at T17, their values decreased in B- and R-supplemented plants (Fig. 2F,G).

Chl $\boldsymbol{a}$ fluorescence analysis: No significant variations were observed for $\Phi_{\mathrm{PSII}}, \mathrm{F}_{\mathrm{v}} / \mathrm{F}_{\mathrm{m}}$, $\mathrm{q}_{\mathrm{P}}$ (Fig. $3 A, C, D$ ), and ETR (data not shown), irrespectively to light treatments and time exposure. At T1, W, B, and G induced an increment of $\mathrm{q}_{\mathrm{N}}$ compared with NS $(+60.5,+26.7$, and $+69.6 \%$, respectively) but after $17 \mathrm{~d}, \mathrm{~W}$ - and B-supplemented plants accounted for similar $\mathrm{q}_{\mathrm{N}}$ values as NS, whereas $\mathrm{R}$ and $\mathrm{G}$ light induced a reduction of this parameter (Fig. 3B). Moreover, values of $\mathrm{F}_{\mathrm{v}} / \mathrm{F}_{\mathrm{m}}$ ranged from 0.78 to 0.80 , irrespectively to treatments and time of exposure. 


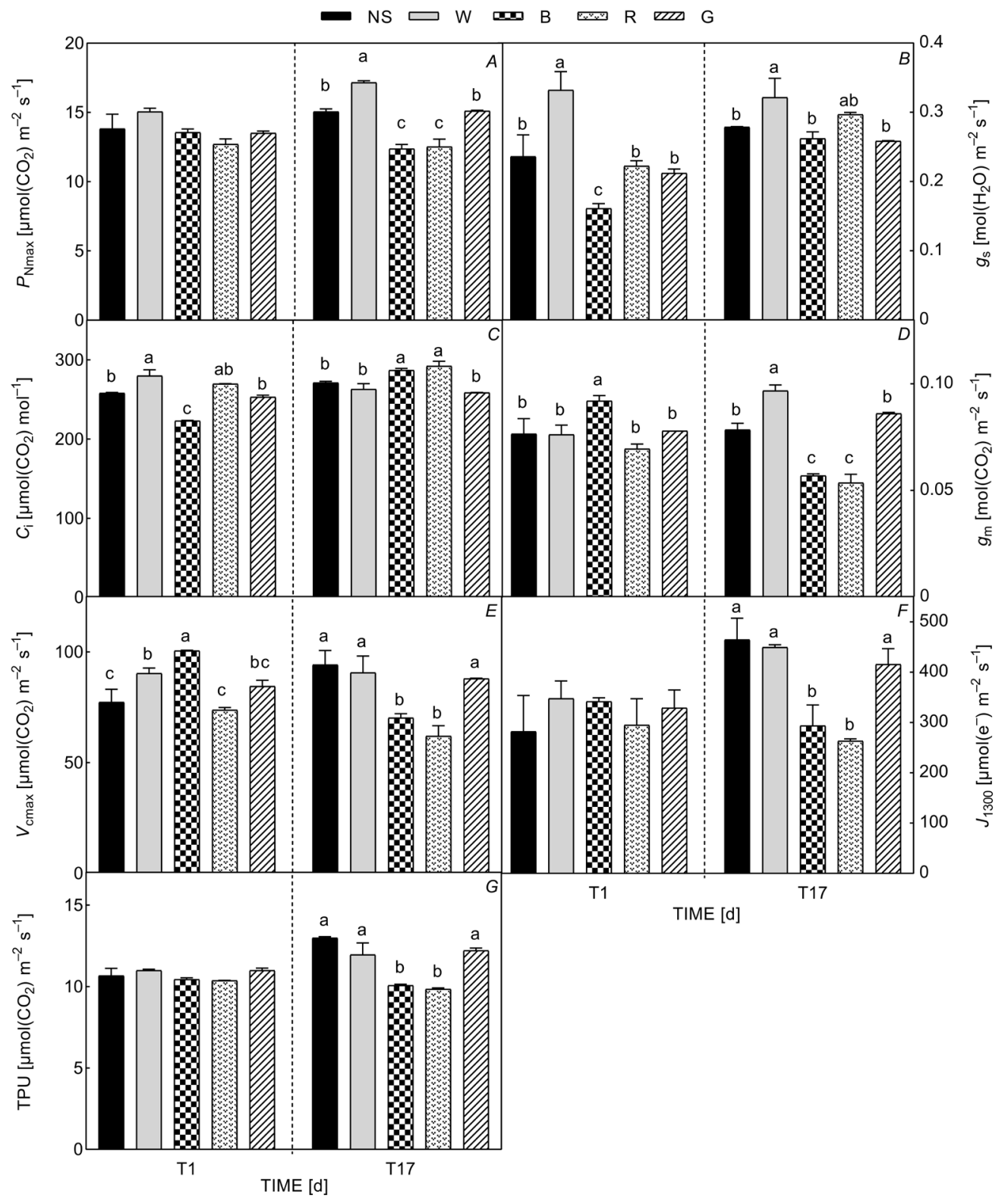

Fig. 2. Light-saturated net photosynthetic rate $\left(P_{\mathrm{Nmax}}\right)(A)$, stomatal conductance $\left(g_{\mathrm{s}}\right)(B)$, intercellular $\mathrm{CO}_{2}$ concentration $\left(C_{\mathrm{i}}\right)(C)$, mesophyll conductance $\left(g_{\mathrm{m}}\right)(D)$, maximum rate of carboxylation of Rubisco $\left(V_{\mathrm{cmax}}\right)(E)$, electron transport obtained at saturating light of $1,300 \mu \mathrm{mol}$ (photon) $\mathrm{m}^{-2} \mathrm{~s}^{-1}\left(J_{1300}\right)(F)$, and triose phosphate utilization rate (TPU) $(G)$ detected in strawberry leaves. Values were recorded after 1 and $17 \mathrm{~d}$ of light supplementation (T1 and T17). Treatments: nonsupplemented control (NS), white light (W - R:G:B, $1: 1: 1)$, blue (B), red (R), and green $(G)$ light supplementation. Means $( \pm \mathrm{SE}, n=3)$ with different letters are significantly different after one-way ANOVA followed by Tukey's multiple range post-hoc test $(P \leq 0.05)$. The absence of letters indicates no significance of the $\mathrm{F}$ ratio.

Chl, flavonoid index, and NBI analysis: At T1, no significant differences in NBI were observed at the adaxial leaf surface, while at the abaxial side, only $\mathrm{R}$ light induced a decline of this parameter (Table 1). At T17, W and $\mathrm{G}$ induced an increment of NBI with G-supplemented plants which accounted for the highest values at the adaxial leaf side. Conversely, B depressed the NBI while R light did not induce significant differences as compared to NS plants. At the abaxial surface, NBI values were higher than those of NS, in order of G, W, and R; B did not affect this parameter.

For the Chl index, at T1, the only detected difference was related to $\mathrm{R}$ light which induced a significant reduction of this index at both leaf surfaces. Conversely, at $\mathrm{T} 17, \mathrm{~W}$ induced a $\mathrm{Chl}$ boost at each leaf face, whilst $\mathrm{G}$ only promoted the $\mathrm{Chl}$ index increment at the abaxial side; B- and R-supplemented and NS plants shared similar Chl index values. 


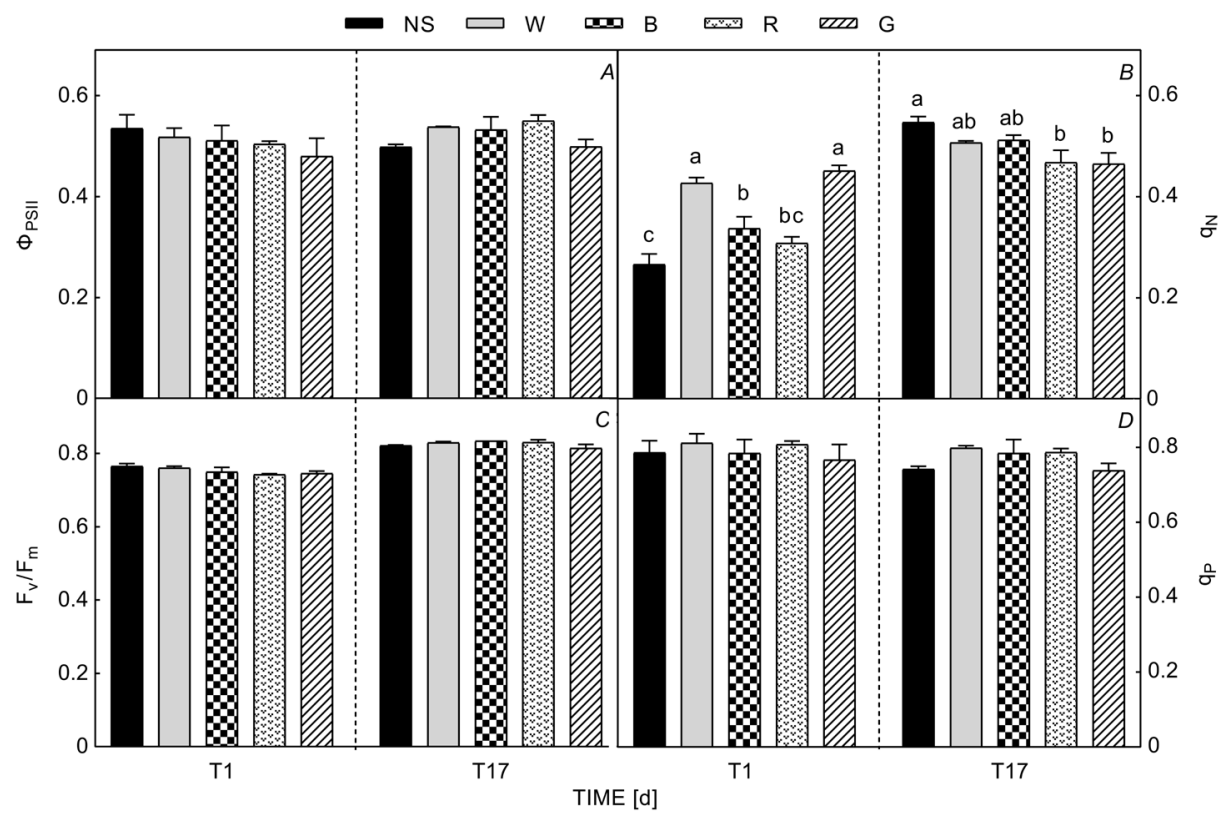

Fig. 3. Values of operational quantum yield $\left(\Phi_{\mathrm{PSII}}\right)(A)$, nonphotochemical quenching coefficient $\left(\mathrm{q}_{\mathrm{N}}\right)(B)$, maximum quantum yield $\left(\mathrm{F}_{\mathrm{v}} / \mathrm{F}_{\mathrm{m}}\right)(C)$, and photochemical quenching coefficient $\left(\mathrm{q}_{\mathrm{P}}\right)(D)$ of PSII detected in strawberry leaves. Values were recorded after 1 and $17 \mathrm{~d}$ of light supplementation (T1 and T17). Treatments: nonsupplemented control (NS), white light (W - R:G:B, 1:1:1), blue (B), red $(\mathrm{R})$, and green $(G)$ light supplementation. Means $( \pm \mathrm{SE}, n=3)$ with different letters are significantly different after one-way $A N O V A$ followed by Tukey's multiple range post-hoc test $(P \leq 0.05)$. The absence of letters indicates no significance of the $\mathrm{F}$ ratio.

Table 1. Nitrogen balance index (NBI), chlorophyll (Chl) and flavonoid (Flav) index related to adaxial and abaxial strawberry leaf surface. Values were recorded after 1 and $17 \mathrm{~d}$ of light supplementation (T1 and T17). Treatments: nonsupplemented control (NS), white light (W - R:G:B, 1:1:1), blue (B), red (R), and green (G) light supplementation. In each column, means $( \pm \mathrm{SE}, n=9)$ with different letters are significantly different after one-way ANOVA followed by Tukey's multiple range post-hoc test $(P \leq 0.05)$. The absence of the letters indicates no significance of the $\mathrm{F}$ ratio.

\begin{tabular}{|c|c|c|c|c|c|c|c|}
\hline \multirow[t]{2}{*}{ Leaf surface } & \multirow[t]{2}{*}{ Treatment } & \multicolumn{3}{|l|}{$\mathrm{T} 1$} & \multicolumn{3}{|l|}{$\mathrm{T} 17$} \\
\hline & & NBI & Chl & Flav & NBI & Chl & Flav \\
\hline \multirow[t]{5}{*}{ Adaxial } & NS & $21.0 \pm 3.3$ & $34.0 \pm 2.7^{\mathrm{a}}$ & $1.64 \pm 0.17^{\mathrm{ab}}$ & $20.4 \pm 2.2^{\mathrm{c}}$ & $32.5 \pm 4.3^{b}$ & $1.59 \pm 0.10^{\mathrm{bc}}$ \\
\hline & $\mathrm{W}$ & $21.0 \pm 3.6$ & $35.8 \pm 2.6^{\mathrm{a}}$ & $1.75 \pm 0.24^{\mathrm{a}}$ & $22.9 \pm 2.6^{b}$ & $38.3 \pm 3.2^{\mathrm{a}}$ & $1.68 \pm 0.08^{\mathrm{b}}$ \\
\hline & $\mathrm{B}$ & $22.1 \pm 4.1$ & $35.2 \pm 2.2^{\mathrm{a}}$ & $1.64 \pm 0.26^{\mathrm{ab}}$ & $16.6 \pm 3.1^{\mathrm{d}}$ & $31.7 \pm 6.0^{\mathrm{b}}$ & $1.92 \pm 0.15^{\mathrm{a}}$ \\
\hline & $\mathrm{R}$ & $18.6 \pm 1.9$ & $29.6 \pm 2.9^{b}$ & $1.59 \pm 0.03^{\mathrm{ab}}$ & $21.7 \pm 1.6^{\mathrm{bc}}$ & $34.0 \pm 1.7^{\mathrm{b}}$ & $1.46 \pm 0.38^{c}$ \\
\hline & $\mathrm{G}$ & $23.5 \pm 3.5$ & $34.0 \pm 2.8^{\mathrm{a}}$ & $1.46 \pm 0.14^{\mathrm{b}}$ & $25.0 \pm 1.0^{\mathrm{a}}$ & $37.6 \pm 2.7^{\mathrm{ab}}$ & $1.50 \pm 0.09^{\mathrm{bc}}$ \\
\hline \multirow[t]{5}{*}{ Abaxial } & NS & $31.5 \pm 5.1^{\mathrm{a}}$ & $33.8 \pm 2.2^{\mathrm{a}}$ & $1.09 \pm 0.15$ & $26.0 \pm 3.8^{c}$ & $32.0 \pm 4.3^{\mathrm{b}}$ & $1.23 \pm 0.05^{\mathrm{ab}}$ \\
\hline & $\mathrm{W}$ & $31.0 \pm 4.3^{\mathrm{a}}$ & $35.5 \pm 3.2^{\mathrm{a}}$ & $1.16 \pm 0.08$ & $31.8 \pm 2.5^{\mathrm{ab}}$ & $37.7 \pm 2.7^{\mathrm{a}}$ & $1.19 \pm 0.04^{\mathrm{b}}$ \\
\hline & $\mathrm{B}$ & $31.7 \pm 3.1^{\mathrm{a}}$ & $34.7 \pm 1.7^{\mathrm{a}}$ & $1.10 \pm 0.08$ & $25.9 \pm 4.8^{c}$ & $32.2 \pm 5.9^{\mathrm{b}}$ & $1.25 \pm 0.10^{\mathrm{a}}$ \\
\hline & $\mathrm{R}$ & $25.9 \pm 3.2^{b}$ & $28.8 \pm 2.6^{\mathrm{b}}$ & $1.12 \pm 0.09$ & $29.3 \pm 2.3^{b}$ & $34.7 \pm 1.9^{\mathrm{ab}}$ & $1.19 \pm 0.07^{\mathrm{b}}$ \\
\hline & G & $31.0 \pm 4.4^{\mathrm{a}}$ & $34.2 \pm 2.6^{\mathrm{a}}$ & $1.11 \pm 0.10$ & $33.1 \pm 1.8^{\mathrm{a}}$ & $37.3 \pm 2.6^{\mathrm{a}}$ & $1.11 \pm 0.03^{\mathrm{c}}$ \\
\hline
\end{tabular}

Flavonoid index values did not differ from the control at the early stage of light treatments, irrespective of the leaf surface, but at $\mathrm{T} 17$, the highest value was recorded at the adaxial surface in B-treated plants, while G promoted a reduction of this index at the abaxial leaf side.

Chl, carotenoid, and tocopherol content determination: At $\mathrm{T} 1, \mathrm{R}$ induced a significant increment of total Chl content $(+25.9 \%$ compared with NS) due to a concomitant rise of Chl $a$ and Chl $b$ contents (Table 2). After $17 \mathrm{~d}$ of light supplementation, no differences emerged in Chl $a$ content between treatments and control. At this sampling time, $\mathrm{R}$ and $\mathrm{B}$ induced a reduction in $\mathrm{Chl} b$ content (-27.1\% in both treatments), and $\mathrm{Chl}(a+b)$ was reduced under R light ( $-28.1 \%$ compared with NS; Table 2). Concerning the $\mathrm{Chl} a / b$ ratio, both $\mathrm{R}$ and $\mathrm{G}$ did not induce significant differences as compared with NS, while plants supplemented with W light showed the highest value 
$(1.99 \pm 0.32)$, while plants under $\mathrm{B}$ were the lowest one $(1.21 \pm 0.13)$. At $\mathrm{T} 17$, there were no statistical differences between treatments and NS plants, except for B-supplemented plants in which the highest $\mathrm{Chl} a / b$ ratio was recorded $(2.24 \pm 0.29)$.

About xanthophylls (Table 3), G light significantly enhanced violaxanthin content. Antheraxanthin and zeaxanthin contents increased in all the treatments, with a maximum content measured under $\mathrm{G}$ light for zeaxanthin, but after $17 \mathrm{~d}$, no significant differences emerged between treatments and control plants in antheraxanthin content, while $\mathrm{R}$ resulted as the only light source able to promote a higher zeaxanthin content. At T1, VAZ improvement was significant under $G$ light, while at $T 17$ both $G$ and $\mathrm{R}$ treatments enhanced the total amount of xanthophyll cycle components. DEPS index increased in all the supplemented plants at T1 (reaching the highest values under $\mathrm{W}$ and $\mathrm{B}$ ), but at T17, no statistical differences were recorded between LED lights vs. NS.

Lutein contents increased at $\mathrm{T} 1$ with $\mathrm{B}, \mathrm{R}$, and $\mathrm{G}$ supplementation compared with $\mathrm{NS}(+20.5,+35.1$, and $+35.1 \%$, respectively), but at $\mathrm{T} 17$, only $\mathrm{B}$ and $\mathrm{G}$ treatments were truly effective for enhancing its content $(+28.2$ and $+20.6 \%$, respectively; Table 4$)$. W light enhanced $\beta$-carotene content at T1 $(+32.1 \%)$, but after $17 \mathrm{~d}$, all the light treatments stimulated the content of this carotenoid, except for R-supplemented plants whose values remained similar to those of NS ones (Table 4). No trace of $\alpha$-carotene was detected irrespective of light treatment and time of exposure (data not shown). At T1, Car/Chl ratio was enhanced by $\mathrm{B}$ treatment $(+37.4 \%$ compared with NS), whereas at T17, R light supplementation only induced significant differences compared with NS and W ( +68.8 and $+49.9 \%$, respectively). The content of $\alpha$-tocopherol increased in R-supplemented plants at $\mathrm{T} 1$ ( $+34.9 \%$ compared with NS), while the highest value was observed in plants grown with B-enriched light, which at T1 showed, conversely, the lowest accumulation (Table 4). Notably, at T17, R-supplemented plants showed the lowest values of $\alpha$-tocopherol.

Superoxide anion determination: An increase in ${ }^{\circ} \mathrm{O}_{2}{ }^{-}$was initially reported under $\mathrm{W}$ and $\mathrm{R}$ light $(+37.1$ and $+28.9 \%$ compared with NS), while the contents measured in plants subjected to $B$ and $G$ light enrichment did not differ from those found in NS counterparts. After $17 \mathrm{~d}, \mathrm{~W}$ and B treatments resulted in the highest ${ }^{\circ} \mathrm{O}_{2}^{-}$production, followed by $\mathrm{R}$ light. $\mathrm{G}$ treatment did not enhance superoxide anion content nor at T1 or T17 compared with NS (Fig. 4).

\section{Discussion}

Light enrichment via specific wavebands is nowadays feasible by LEDs, which are inexpensive and eco-friendly lighting devices and therefore can be considered as a valid tool to stimulate the photosynthetic process in indoor cultivation, especially in light-limiting periods (Bantis et al. 2018, Matysiak and Kowalski 2019). Different light spectra can selectively stimulate leaf photoreceptors, which in turn induce distinct signalling transduction pathways and gene regulation affecting several physiological and biochemical processes that drive leaf photosynthesis (Wang et al. 2009, Landi et al. 2020). Therefore, a deep knowledge of the waveband-dependent effects of light enrichment by LED in specific crop species (e.g., strawberry - Choi et al. 2015) is essential for efficient management of their indoor cultivation.

To date, most studies agree that there are three main players (among physiological and biochemical processes) that drive photosynthesis in plants: (1) the $\mathrm{CO}_{2}$ diffusion through stomata $\left(g_{\mathrm{s}}\right)$, (2) the $\mathrm{CO}_{2}$ diffusion through the mesophyll $\left(g_{\mathrm{m}}\right)$, and (3) the Rubisco carboxylation activity (Galmés et al. 2017, Gago et al. 2020). In the present study, the decreased $g_{\mathrm{s}}$ found at T1 under supplemental B light did not affect $P_{\text {Nmax }}$. The preservation of $P_{\text {Nmax }}$ (at values similar to those found in NS) was due to the concomitant increase of the efficiency in the diffusion of $\mathrm{CO}_{2}$ through the mesophyll $\left(g_{\mathrm{m}}\right)$ and in the maximum carboxylation rate by Rubisco $\left(V_{\text {cmax }}\right)$, which resulted in reduced $C_{\mathrm{i}}$. Changes in these photosynthetic traits highlight that fine coordination between $\mathrm{CO}_{2}$ diffusion and fixation is critical for achieving the maximum photosynthetic capacity (Galmés et al. 2017, Hu et al. 2019). However, opposite results concerning the effects of blue light on $g_{\mathrm{m}}$ were detected in Nicotiana tabacum, Platanus orientalis, and Populus trichocarpa (Loreto et al. 2009, Momayyezi and Guy 2017), where a reduction in mesophyll conductance was measured immediately

Table 2. Chlorophyll $a(\mathrm{Chl} a)$, chlorophyll $b(\mathrm{Chl} b)$, total chlorophyll $[\mathrm{Chl}(a+b)]$ and chlorophyll $a$-to-chlorophyll $b$ ratio $(\mathrm{Chl} a / b)$ values detected in strawberry leaves. Values were recorded after 1 and $17 \mathrm{~d}$ of light supplementation (T1 and T17). Treatments: nonsupplemented control (NS), white light (W - R:G:B, 1:1:1), blue (B), red (R), and green (G) light supplementation. Means ( \pm SE, $n=3$ ) with different letters are significantly different after one-way ANOVA followed by Tukey's multiple range post-hoc test $(P \leq 0.05)$. FM - fresh mass.

\begin{tabular}{lllllllll}
\hline \multirow{2}{*}{ Treatment } & \multicolumn{2}{l}{$\mathrm{Chl} a\left[\mu \mathrm{mol} \mathrm{g}^{-1}(\mathrm{FM})\right]$} & \multicolumn{2}{l}{$\mathrm{Chl} b[\mu \mathrm{mol} \mathrm{g}(\mathrm{FM})]$} & \multicolumn{2}{l}{$\mathrm{Chl}(a+b)\left[\mu \mathrm{mol} \mathrm{g}^{-1}(\mathrm{FM})\right]$} & \multicolumn{2}{l}{$\mathrm{Chl} a / b$} \\
& $\mathrm{~T} 1$ & $\mathrm{~T} 17$ & $\mathrm{~T} 1$ & $\mathrm{~T} 17$ & $\mathrm{~T} 1$ & $\mathrm{~T} 17$ & $\mathrm{~T} 1$ & $\mathrm{~T} 17$ \\
\hline $\mathrm{NS}$ & $1.00 \pm 0.15^{\mathrm{b}}$ & $0.79 \pm 0.02^{\mathrm{ab}}$ & $0.65 \pm 0.09^{\mathrm{b}}$ & $0.59 \pm 0.02^{\mathrm{a}}$ & $1.64 \pm 0.24^{\mathrm{b}}$ & $1.39 \pm 0.00^{\mathrm{a}}$ & $1.55 \pm 0.04^{\mathrm{b}}$ & $1.33 \pm 0.09^{\mathrm{b}}$ \\
$\mathrm{W}$ & $1.22 \pm 0.16^{\mathrm{ab}}$ & $0.81 \pm 0.08^{\mathrm{ab}}$ & $0.62 \pm 0.04^{\mathrm{b}}$ & $0.59 \pm 0.02^{\mathrm{a}}$ & $1.84 \pm 0.14^{\mathrm{ab}}$ & $1.40 \pm 0.09^{\mathrm{a}}$ & $1.99 \pm 0.32^{\mathrm{a}}$ & $1.37 \pm 0.12^{\mathrm{b}}$ \\
$\mathrm{B}$ & $0.77 \pm 0.04^{\mathrm{b}}$ & $0.94 \pm 0.02^{\mathrm{a}}$ & $0.64 \pm 0.08^{\mathrm{b}}$ & $0.43 \pm 0.06^{\mathrm{b}}$ & $1.41 \pm 0.09^{\mathrm{b}}$ & $1.37 \pm 0.08^{\mathrm{a}}$ & $1.21 \pm 0.13^{\mathrm{c}}$ & $2.24 \pm 0.29^{\mathrm{a}}$ \\
$\mathrm{R}$ & $1.27 \pm 0.16^{\mathrm{a}}$ & $0.57 \pm 0.13^{\mathrm{b}}$ & $0.80 \pm 0.03^{\mathrm{a}}$ & $0.43 \pm 0.08^{\mathrm{b}}$ & $2.07 \pm 0.19^{\mathrm{a}}$ & $1.00 \pm 0.20^{\mathrm{b}}$ & $1.60 \pm 0.17^{\mathrm{b}}$ & $1.31 \pm 0.11^{\mathrm{b}}$ \\
$\mathrm{G}$ & $1.05 \pm 0.11^{\mathrm{ab}}$ & $0.66 \pm 0.18^{\mathrm{b}}$ & $0.64 \pm 0.06^{\mathrm{b}}$ & $0.64 \pm 0.03^{\mathrm{a}}$ & $1.69 \pm 0.14^{\mathrm{b}}$ & $1.29 \pm 0.19^{\mathrm{a}}$ & $1.63 \pm 0.16^{\mathrm{b}}$ & $1.04 \pm 0.30^{\mathrm{b}}$ \\
\hline
\end{tabular}




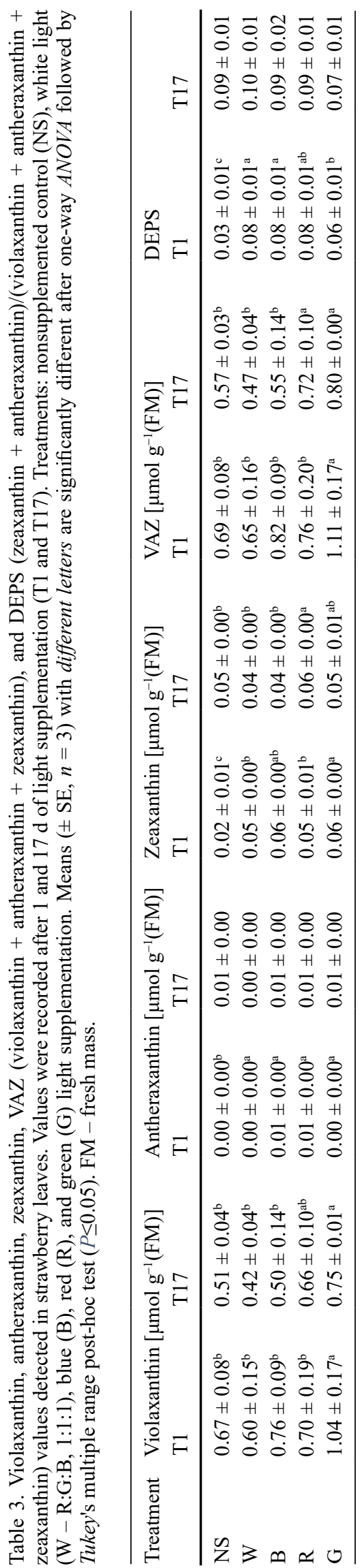

after the exposition to blue light. It is possible to speculate that the different experimental setup was responsible for this apparent contradiction (e.g., light quality and intensity, environmental conditions, and plant species). To elucidate this pattern, further studies should be conducted to understand the positive transient effect (at $17 \mathrm{~d}$, B plants showed a strong decrease in $g_{\mathrm{m}}$ values indeed) on $g_{\mathrm{m}}$ of supplemental blue light on leaves.

At T17, both $g_{\mathrm{s}}$ and $g_{\mathrm{m}}$ were higher in W-supplemented plants. Given that other photosynthetic parameters, such as $V_{\text {cmax }}, J_{1300}$, and TPU, did not change in $\mathrm{W}$-supplemented plants, it is conceivable that $\mathrm{CO}_{2}$ diffusive limitations were the main photosynthesis limitations under these experimental conditions. The decrease in $P_{\text {Nmax }}$ observed in $\mathrm{B}$ and $\mathrm{R}$ treatments was attributable to the concomitant limitation occurring at physiological $\left(g_{\mathrm{m}}\right)$ and biochemical processes $\left(V_{\text {cmax }}, J_{1300}\right.$, and TPU). At T17, B treatment induced a significant reduction of $g_{\mathrm{m}}$, and this response could be partially due to the chloroplast movements, whilst the reduction in $V_{\text {cmax }}$ values can be related to the depression in carbonic anhydrase activity by B light (Loreto et al. 2009, Momayyezi and Guy 2017). The reduction in photosynthetic performance observed under $\mathrm{R}$ treatment was likely related to the reduction in Rubisco content (Muneer et al. 2014), and in particular the small subunit (Su et al. 2014), or to a lower leaf nitrogen content, responsible, in turn, for a lower chlorophyll content (Kim et al. 2004), as also observed in our experiments (Tables 1, 2). Notably, G light did not exert any effect on gas-exchange parameters.

Red, green, blue LED light did not induce any remarkable effect on PSII photochemical phase and, at both $\mathrm{T} 1$ and $\mathrm{T} 17$, plants belonging to all the treatments showed similar values in maximum quantum yield of PSII $\left(F_{v} / F_{m}\right)$, which is supportive for no damages to PSII. Irrespectively to the time of exposure, in our experiment, any treatment impacted the effective efficiency of PSII $\left(\Phi_{\mathrm{PSII}}\right)$ and the values of $\mathrm{q}_{\mathrm{P}}$ as well, whereas Wang et al. (2009) reported that $\Phi_{\text {PSII }}$ significantly decreased in cucumber plants subjected to different LED lights (in the order: blue, purple, green, yellow, and red) as a consequence of $\mathrm{q}_{\mathrm{P}}$ reduction. In contrast to our findings, where $\mathrm{R}$ and $\mathrm{G}$ reduced the values of $\mathrm{q}_{\mathrm{N}}$ at $\mathrm{T} 17$, red and green light enhanced nonphotochemical quenching in rice and cucumber plants (Chen et al. 2014, Wang et al. 2009, respectively). The discrepancy between our results and those available in the literature from plants grown under monochromatic environments underlines the need to add knowledge on the effect of ambient light enrichment by specific wavebands on the photosynthetic process. This is evidence that the photosynthetic behaviour in waveband-specific supplemented plants cannot be simply predicted from those results obtained in plants growing in monochromatic environments.

Under optimal growing conditions, plants usually favour their primary metabolism whereas in case of stress, e.g., nitrogen deficiency, plant metabolism turns towards an increased biosynthesis of secondary metabolites, e.g., polyphenols (Demotes-Mainard et al. 2008). In literature, few experiments tested the effect of single-colour LED 
Table 4. Lutein, $\beta$-carotene, carotenoid-to-chlorophyll ratio (Car/Chl), and $\alpha$-tocopherol levels detected in strawberry leaves. Values were recorded after 1 and $17 \mathrm{~d}$ of light supplementation (T1 and T17). Treatments: nonsupplemented control (NS), white light (W - R:G:B, 1:1:1), blue (B), red (R), and green (G) light supplementation. Means ( $\pm \mathrm{SE}, n=3$ ) with different letters are significantly different after one-way ANOVA followed by Tukey's multiple range post-hoc test $(P \leq 0.05)$.

\begin{tabular}{lllllllll}
\hline \multirow{2}{*}{ Treatment } & \multicolumn{2}{l}{ Lutein $[\mu \mathrm{mol} \mathrm{g}(\mathrm{FM})]$} & \multicolumn{2}{l}{$\beta$-carotene $[\mu \mathrm{mol} \mathrm{g}(\mathrm{FM})]$} & \multicolumn{2}{l}{ Car/Chl } & \multicolumn{2}{c}{$\alpha$-tocopherol $\left[\mu \mathrm{mol} \mathrm{g} \mathrm{g}^{-1}(\mathrm{FM})\right]$} \\
& $\mathrm{T} 1$ & $\mathrm{~T} 17$ & $\mathrm{~T} 1$ & $\mathrm{~T} 17$ & $\mathrm{~T} 1$ & $\mathrm{~T} 17$ & $\mathrm{~T} 1$ & $\mathrm{~T} 17$ \\
\hline $\mathrm{NS}$ & $6.16 \pm 0.65^{\mathrm{b}}$ & $5.82 \pm 0.39^{\mathrm{b}}$ & $0.56 \pm 0.06^{\mathrm{b}}$ & $0.32 \pm 0.07^{\mathrm{b}}$ & $4.55 \pm 0.64^{\mathrm{b}}$ & $4.84 \pm 0.24^{\mathrm{b}}$ & $7.39 \pm 1.21^{\mathrm{b}}$ & $5.79 \pm 0.07^{\mathrm{b}}$ \\
$\mathrm{W}$ & $6.43 \pm 0.84^{\mathrm{b}}$ & $6.53 \pm 0.88^{\mathrm{ab}}$ & $0.74 \pm 0.02^{\mathrm{a}}$ & $0.56 \pm 0.06^{\mathrm{a}}$ & $4.25 \pm 0.49^{\mathrm{b}}$ & $5.45 \pm 1.00^{\mathrm{b}}$ & $7.29 \pm 0.90^{\mathrm{bc}}$ & $6.07 \pm 0.62^{\mathrm{b}}$ \\
$\mathrm{B}$ & $7.42 \pm 0.63^{\mathrm{a}}$ & $7.46 \pm 0.42^{\mathrm{a}}$ & $0.53 \pm 0.07^{\mathrm{b}}$ & $0.58 \pm 0.11^{\mathrm{a}}$ & $6.25 \pm 0.81^{\mathrm{a}}$ & $6.28 \pm 0.43^{\mathrm{ab}}$ & $5.81 \pm 0.32^{\mathrm{c}}$ & $7.11 \pm 0.12^{\mathrm{a}}$ \\
$\mathrm{R}$ & $8.32 \pm 0.69^{\mathrm{a}}$ & $6.76 \pm 0.26^{\mathrm{ab}}$ & $0.63 \pm 0.09^{\mathrm{ab}}$ & $0.44 \pm 0.01^{\mathrm{b}}$ & $4.74 \pm 0.76^{\mathrm{b}}$ & $8.17 \pm 1.98^{\mathrm{a}}$ & $9.97 \pm 0.62^{\mathrm{a}}$ & $4.22 \pm 0.93^{\mathrm{c}}$ \\
$\mathrm{G}$ & $8.32 \pm 0.39^{\mathrm{a}}$ & $7.02 \pm 0.63^{\mathrm{a}}$ & $0.58 \pm 0.07^{\mathrm{b}}$ & $0.60 \pm 0.06^{\mathrm{a}}$ & $5.96 \pm 0.70^{\mathrm{ab}}$ & $6.56 \pm 0.52^{\mathrm{ab}}$ & $5.86 \pm 0.93^{\mathrm{bc}}$ & $5.65 \pm 0.06^{\mathrm{b}}$ \\
\hline
\end{tabular}

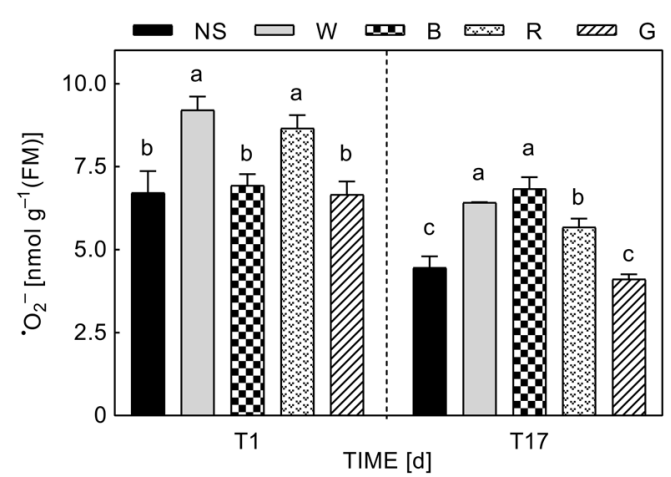

Fig. 4. Superoxide anion $\left(\cdot \mathrm{O}_{2}^{-}\right)$content detected in strawberry leaves. Values were recorded after 1 and $17 \mathrm{~d}$ of light supplementation (T1 and T17). Treatments: nonsupplemented control (NS), white light (W - R:G:B, 1:1:1), blue (B), red (R), and green $(G)$ light supplementation. Means $( \pm \mathrm{SE}, n=3)$ with different letters are significantly different after one-way ANOVA followed by Tukey's multiple range post-hoc test $(P \leq 0.05)$. FM - fresh mass.

light supplementation over ambient light, while most of the studies were conducted in growth chambers with selected wavebands: these differences in experimental conditions make the comparison with literature, again, very difficult. Anyway, it is reported that polychromatic light provided in growth chambers enhanced NBI in tatsoi (Viršilè et al. 2019), while red and far-red lights depressed NBI values in hazelnut plantlets (Silvestri et al. 2019). To date, no information is available for green and blue light supplementation. From our results, we can assume that $\mathrm{W}$ treatment stimulated photosynthesis and primary metabolism as already observed through gas exchange analysis. Previous studies conducted in green- and purple-leafed sweet basil showed that red light supplementation induced a lower chlorophyll accumulation compared to white and blue lights (Matysiak and Kowalski 2019); green light diminished Chl content in Brassica rapa var. chinensis (Mickens et al. 2019), while, according to Choi et al. (2015), lower Chl accumulation was observed in strawberry plants under blue light. No significant differences in terms of Chl content emerged in other species when subjected to specific wavebands
(Bagdonavičienė et al. 2015, Matysiak and Kowalski 2019), thereby suggesting that supplementation of selective wavebands and Chl content relation was speciesspecific and also dependent on the experimental conditions. Finally, according to our findings, it was reported that blue LED light supplementation stimulated phenol biosynthesis in various leafy greens (Bantis et al. 2016, Matysiak and Kowalski 2019). The present experiment highlights that B treatment enhanced flavonoid contents in the adaxial leaf surface, while a significant decrease was observed under $\mathrm{G}$ light on the abaxial side. Generally, the enhancement in leaf flavonoid content is a suitable marker for plant acclimation to unfavourable conditions (Viršile et al. 2018), but phenylpropanoid metabolism boost can also be attributable to selective stimulation of this branch of secondary metabolism by B wavelengths, while $\mathrm{G}$ light has often opposite effects (Landi et al. 2020).

Our work did not underline significant differences between LED-supplemented and NS plants in terms of $\mathrm{Chl}$ content induced by light supplementation, except for a final reduction under $\mathrm{R}$ treatment. Choi et al. (2015) reported that blue light was less effective for Chl stimulation in strawberry plants, while in other cases blue light, more than red, was able to promote $\mathrm{Chl}$ accumulation (Mizuno et al. 2011, Li et al. 2012). Hernández and Kubota (2014) also found higher Chl concentration in cucumber leaves grown under ambient light and supplemented with blue LEDs. According to our results, Wang et al. (2009) reported that the $\mathrm{Chl} a / b$ ratio was greater under $100 \%$ blue light in cucumber plants, while the lowest value was obtained in plants grown under green light. Variation in the $\mathrm{Chl} a / b$ ratio could be related to the ability to balance light absorption by the two photosystems: an increase in Chl $a / b$ was the result of an optimal acclimation to high light (Kitajima and Hogan 2003), as also observed in our experiments under $\mathrm{B}$ light. Moreover, $\mathrm{Chl} a / b$ variation can be considered as a valid marker of $\mathrm{N}$ partition in the leaf (Terashima and Hikosaka 1995). In our work, the highest Chl $a / b$ ratio was measured in plants subjected to B enrichment which, in turn, had the lowest NBI value. According to this hypothesis, an increase of the $\mathrm{Chl} a / b$ ratio was observed when $\mathrm{N}$ availability decreased, especially under high-light conditions. Indeed, when $\mathrm{N}$ supply becomes a limiting factor, $\mathrm{N}$ is mainly allocated to protein-based structures of 
PSII core at the expanses of $\mathrm{N}$ allocation to Rubisco. At the same time, N allocation to LHCII (characterized by greater $\mathrm{Chl} b$ content), is maintained at a similar level (Hikosaka and Terashima 1995). Consequently, PSII/LHCII and Chl $a / b$ ratio most likely increase with the decrease of $\mathrm{N}$ availability (Kitajima and Hogan 2003). In addition, Chl $a / b$ ratio variation is correlated with PSII lightharvesting antenna size changes (Leong and Anderson 1984) and PSII:PSI content, as Chl $a / b$ ratio might be related to the reduction of $\Phi_{\mathrm{PSII}}$ (Wang et al. 2009). There was no evidence in our work to verify this hypothesis.

Besides chlorophylls, carotenoids carry out the fundamental role of plant protection against photooxidative damage and are closely related to photosynthesis as they assist chlorophylls in light absorption (Jahns and Holzwarth 2012, Brazaityte et al. 2015). Carotenoids are pivotal pigments for both their direct scavenger capacity and/or the nonphotochemical quenching activation (Jahns and Holzwarth 2012); light intensity (Thoma et al. 2020), as well as different light spectra, can strongly influence the carotenoid metabolism (Landi et al. 2020). It has been therefore reported that sunlight exposed leaves accumulated more carotenoids ( $\beta$-carotene and xanthophylls; Czeczuga 1987, Demmig-Adams and Adams 1992, Demmig-Adams et al. 1996).

Under light excess conditions, an accumulation of zeaxanthin occurs in concomitance with electron transport saturation and PSII overreduction to avoid undesirable dissipation of excitation energy (e.g., Mehler reaction and ROS production) (Kalituho et al. 2007). In our experiments, a build-up of zeaxanthin at T1 in plants subjected to light enrichment was observed (as compared to NS plants), which is supportive for their need to be photoprotected after a 1-d imposition of supplemented light, e.g., via the activation of the zeaxanthin-dependent quenching, $\mathrm{q}_{\mathrm{z}}$, and feedback de-excitation $\mathrm{q}_{\mathrm{E}}$ (Li et al. 2002) of nonphotochemical quenching. Indeed, the level of DEPS increased in parallel in plants subjected to light enrichment, irrespectively to the light spectra. However, after $17 \mathrm{~d}$, only zeaxanthin contents remained higher in R-supplemented plants than that in NS ones, which highlights the capability of the strawberry plants grown under $\mathrm{W}, \mathrm{B}$, and $\mathrm{G}$ lights to acclimate to higher irradiances after $17 \mathrm{~d}$ of supplementation. This is in accordance with a higher level of VAZ observed in R-supplemented plants than NS ones, as the unchanged level of DEPS recorded at T17. Notably, a higher level of VAZ measured at both $\mathrm{T} 1$ and $\mathrm{T} 17$ in G-supplemented plants hints at the plant necessity to increase the content of oxygenated carotenoids once the plants are subjected to those wavebands of the solar spectrum which are normally poorly absorbed by the leaf (Brazaitytė et al. 2015).

Lutein is the most abundant xanthophyll in higher plants and supports several pivotal functions in the photosynthetic apparatus, including the structural stabilization of antenna proteins, formation of light-harvesting complexes, quenching of ${ }^{3} \mathrm{Chl}$ states, and it has been also proposed to be involved in the quenching of ${ }^{1} \mathrm{Chl}$ (Jahns and Holzwarth 2012). The increase in lutein content measured at $\mathrm{T} 1$ in all the plants supplemented with $\mathrm{R}$,
$B$, and $G$ (but not in $W$ ) further confirms the initial perturbation of photosynthetic apparatus by light enrichment, as above reported in terms of zeaxanthin and DEPS. In this case, the lack of enhancement of lutein in W-supplemented plants can support the need for this carotenoid in cases of the unbalanced level of some particular wavebands instead of in polychromatic light stress. Indeed, at $\mathrm{T} 17$, the lutein content only remained higher in B and $\mathrm{G}$ light, which are the wavebands mostly absorbed by this pigment (Solovchenko 2010).

Among nonoxygenated carotenoids, $\beta$-carotene (the main carotenoid in planta) also plays imperative functions as it is associated with the core of PSI and PSII, and is present in all organisms performing oxygenic photosynthesis (Qin et al. 2015). Our results confirm the accumulation of $\beta$-carotene in plants that sensed increasing light irradiances, but differently from lutein, only $\mathrm{W}$ (polychromatic light) promoted the increment of this carotenoid at T1. This suggests that lutein (the main xanthophyll) and $\beta$-carotene (the main nonoxygenated carotenoid) might play compensatory effects in case of unbalance of the light intensity or light spectra. At T17, the protraction of the light enrichment promoted the accumulation of $\beta$-carotene in all treatments except for $\mathrm{R}$, compared to control. Our findings are in agreement with Samuoliene et al. (2016) who observed that red light did not promote the accumulation of $\beta$-carotene in basil. More solid results are needed to give a consistency of the relationship between light enrichment by selected wavebands and carotenoid metabolism.

Overall, the $\mathrm{Car} / \mathrm{Chl}$ ratio represents a good marker of vegetation photosynthetic activity, developmental changes, and photosynthetic stress responses (Young 1993, Gitelson 2020), which allows physiological and phenological status characterization (Peñuelas et al. 1995, Solovchenko 2010, Zhou et al. 2019). In healthy plants, a constant $\mathrm{Car} / \mathrm{Chl}$ ratio due to conserved stoichiometry of $\mathrm{Chl}$ and photosynthetic Car is also detected, while in stressed or senescing leaves, $\mathrm{Chl}$ and Car content and proportion vary strongly (Gitelson 2020), with a faster reduction of Chl amount over the Car content (Zhou et al. 2019). An increased Car/Chl ratio with increased light intensity revealed the activation of the photoprotection mechanism against excessive light absorption (Lee et al. 2007). In our work, $\mathrm{R}$ supplementation was able to stimulate the activation of the photoprotective mechanism, even though in literature is reported that $100 \%$ blue light induced a higher $\mathrm{Car} / \mathrm{Chl}$ ratio compared to red and white light in tomato plants (Izzo et al. 2020).

It is well known that, when dissipation mechanisms are not sufficient to prevent an excessive light absorption concerning the $\mathrm{CO}_{2}$ fixation ability, plants may incur ROS formation and oxidative burst with harmful effects at cellular/subcellular level (Foyer 2018). Carotenoids and tocopherols are nonenzymatic antioxidants apt for oxidative stress prevention. Tocopherols are fat-soluble compounds, located in plant chloroplast, where they neutralize peroxyl radicals and extinguish ${ }^{1} \mathrm{O}_{2} ; \alpha$-tocopherol is the most abundant in green-leafed plants (Munné-Bosch and Alegre 2002). Only a few reports are available on the 
effect of supplemented light on tocopherol contents. For example, increased $\alpha$-tocopherol content was registered in basil plants cultivated in growth chambers under red light supplementation (Samuoliene et al. 2016). These results are in agreement with our findings, where R-supplemented plants showed the highest content of $\alpha$-tocopherol at T1, which could be a preferential mechanism adopted to protect themselves against photooxidative damage and oxidative stress. Conversely, as stated above, at T17, R-supplemented plants showed a marked loss of $\mathrm{Chl}(a+b)$ and a strong enhancement of the Car/Chl ratio as an alternative photoprotective mechanism. Differently, $\alpha$-tocopherol increased sensibly in B-enriched plants at $\mathrm{T} 17$, supporting a role of this molecule as a radical scavenger in a longer-term exposure, when plants are subjected to the highest energetic (shortest waveband) B-light enrichment.

Among all ROS species, ${ }^{\circ} \mathrm{O}_{2}^{-}$formation is caused by an alteration in photosynthetic reactions due to environmental stresses so that excessive light energy cannot be used for chloroplast ferredoxin $\mathrm{NADP}^{+}$reduction (Asada and Takahashi 1987). Thus, superoxide anion molecules can be generated in two different ways: one derived from the plastoquinone pool, carrying one electron from $\mathrm{Q}_{\mathrm{A}}^{-}$to an oxygen molecule, while the second was produced during Mehler reaction on the PSI acceptor side. Superoxide dismutase (SOD) converted ${ }^{\circ} \mathrm{O}_{2}{ }^{-}$into $\mathrm{H}_{2} \mathrm{O}_{2}$, which in turn was converted in $\mathrm{H}_{2} \mathrm{O}$ by ascorbate peroxidase (Caverzan et al. 2012). In our experiments, the faster increment of oxidative stress (in terms of ${ }^{\circ} \mathrm{O}_{2}^{-}$ production) occurred for $\mathrm{W}$ - and R-supplemented plants as reported at $\mathrm{T} 1$, whereas at $\mathrm{T} 17$, also B-enriched plants showed a higher content of superoxide anion. Our findings agree with Agarwal et al. (2018), in which emerged that blue and red light induced higher oxidative burst. In particular, the highest level of ${ }^{\circ} \mathrm{O}_{2}^{-}$formation observed in the present experiment, promoted by $\mathrm{B}$ light, can be related to the higher energetic level of this waveband (Landi et al. 2020). However, even a condition of $\mathrm{W}$ supplementation (which is composed of 33\% R and 33\% B light) induced a higher generation of ${ }^{\cdot} \mathrm{O}_{2}^{-}$. Notably, $\mathrm{G}$ light nor at T1 or T17 promoted ${ }^{\circ} \mathrm{O}_{2}^{-}$accumulation. We assume, therefore, that $\mathrm{G}$ LED light did not induce oxidative stress enhancement compared to NS plants. The reason behind this effect may be the efficient activation of the xanthophyll cycle and a general carotenoid synthesis stimulation as well as the poor absorbance of these wavebands by the Chl molecules.

In conclusion, $\mathrm{W}$ light treatment was able to spur photosynthesis without any stress macroscopic symptoms nor changes in chlorophyll and flavonoid content. G wavelengths did not induce significant alteration in plant photosynthetic processes and level of oxidative stress; thus G LEDs could be tested in further lightenrichment experiments. Instead, $\mathrm{R}$ and $\mathrm{B}$ lights enhanced the stress levels in strawberry plants and hampered key physiological and biochemical processes that drive leaf photosynthesis which, however, did not result in visible injury. In light of Roberts and Paul (2006) argumentations, that light-mediated ROS production can act as a starter for plant defence responses (including pathogens), further research will investigate the efficiency of less impacting wavelengths (such as $\mathrm{W}$ and $\mathrm{G}$ ) for testing their efficiency in promoting strawberry quality as much as disease resistance.

\section{References}

Able A.J., Guest D.I., Sutherland M.W.: Use of a new tetrazoliumbased assay to study the production of superoxide radicals by tobacco cell cultures challenged with avirulent zoospores of Phytophthora parasitica var nicotianae. - Plant Physiol. 117: 491-499, 1998.

Agarwal A., Dutta Gupta S., Barman M., Mitra A.: Photosynthetic apparatus plays a central role in photosensitive physiological acclimations affecting spinach (Spinacia oleracea L.) growth in response to blue and red photon flux ratios. - Environ. Exp. Bot. 156: 170-182, 2018.

Asada K., Takahashi M.: Production and scavenging of active oxygen in photosynthesis. - In: Kyle D.J., Osmond C.B., Arntzen C.J. (ed.): Photoinhibition. Pp. 228-287. Elsevier, Amsterdam 1987.

Bagdonavičienė A., Jankauskienè J., Čeidaitė A. et al.: The impact of supplemental blue and green LED and HPS lamps lighting effects on the photosynthesis parameters of sweet pepper transplants. - Sodininkystė ir daržininkyste 34: 37-46, 2015.

Ballaré C.J.: Light regulation of plant defense. - Annu. Rev. Plant Biol. 65: 335-363, 2014.

Bantis F., Ouzounis T., Radoglou K.: Artificial LED lighting enhances growth characteristics and total phenolic content of Ocimum basilicum, but variably affects transplant success. Sci. Hortic.-Amsterdam 198: 277-283, 2016.

Bantis F., Smirnakou S., Ouzounis T. et al.: Current status and recent achievements in the field of horticulture with the use of light-emitting diodes (LEDs). - Sci. Hortic.-Amsterdam 235: 437-451, 2018.

Bernacchi C.J., Portis A.R., Nakano H. et al:: Temperature response of mesophyll conductance. Implications for the determination of Rubisco enzyme kinetics and for limitations to photosynthesis in vivo. - Plant Physiol. 130: 1992-1998, 2002.

Bourget C.M.: An introduction to light-emitting diodes. HortScience 43: 1944-1946, 2008.

Brazaitytė A., Sakalauskienè S., Samuolienè G. et al.: The effects of LED illumination spectra and intensity on carotenoid content in Brassicaceae microgreens. - Food Chem. 173: 600-606, 2015.

Caverzan A., Passaia G., Barcellos Rosa S. et al.: Plant responses to stresses: role of ascorbate peroxidase in the antioxidant protection. - Genet. Mol. Biol. 34: 1011-1019, 2012.

Chen C.-C., Huang M.-Y., Lin K.-H. et al.: Effects of light quality on the growth, development and metabolism of rice seedlings (Oryza sativa L.). - Res. J. Biotechnol. 9: 15-24, 2014.

Choi H.G., Moon B.Y., Kang N.J.: Effects of LED light on the production of strawberry during cultivation in a plastic greenhouse and in a growth chamber. - Sci. Hortic.Amsterdam 189: 22-31, 2015.

Cocetta G., Casciani D., Bulgari R. et al.: Light use efficiency for vegetables production in protected and indoor environments. - Eur. Phys. J. Plus 132: 43, 2017.

Czeczuga B.: Carotenoid contents in leaves grown under various light intensities. - Biochem. Syst. Ecol. 15: 523-527, 1987.

Demmig-Adams B., Adams III W.W.: Photoprotection and other responses of plants to high light stress. - Annu. Rev. Plant Phys. 43: 599-626, 1992. 
Demmig-Adams B., Gilmore A.M., Adams III W.W.: In vivo functions of carotenoids in higher plants. - FASEB J. 10: 403-412, 1996.

Demotes-Mainard S., Boumaza R., Meyer S., Cerovic Z.G.: Indicators of nitrogen status for ornamental woody plants based on optical measurements of leaf epidermal polyphenol and chlorophyll contents. - Sci. Hortic.-Amsterdam 115: 377$385,2008$.

Farquhar G.D., von Caemmerer S., Berry J.A.: A biochemical model of photosynthetic $\mathrm{CO}_{2}$ assimilation in leaves of $\mathrm{C}_{3}$ species. Planta 149: 78-90, 1980.

Folta K.M., Childers K.S.: Light as a growth regulator: controlling plant biology with narrow-bandwidth solid-state lighting systems. - HortScience 43: 1957-1964, 2008.

Foyer C.H.: Reactive oxygen species, oxidative signaling and the regulation of photosynthesis. - Environ. Exp. Bot. 154: 134142,2018

Frechilla S., Talbott L.D., Bogomolni R., Zeiger E.: Reversal of blue light-stimulated stomatal opening by green light. - Plant Cell Physiol. 41: 171-176, 2000.

Gago J., Daloso D.M., Carriquí M. et al.: Mesophyll conductance: the leaf corridors for photosynthesis. - Biochem. Soc. T. 48: 429-439, 2020

Gago J., Coopman R.E., Cabrera H.M. et al.: Photosynthesis limitations in three fern species. - Physiol. Plantarum 149: 599-611, 2013.

Galmés J., Molins A., Flexas J., Conesa M.À.: Coordination between leaf $\mathrm{CO}_{2}$ diffusion and Rubisco properties allows maximizing photosynthetic efficiency in Limonium species. Plant Cell Environ. 40: 2081-2094, 2017.

García-Plazaola J., Esteban R.: Determination of chlorophylls and carotenoids by HPLC - Protocol. PrometheusWiki, 2016.

Gitelson A.: Towards a generic approach to remote non-invasive estimation of foliar carotenoid-to-chlorophyll ratio. - J. Plant Physiol. 252: 153227, 2020.

Golovatskaya I.F., Karnachuk R.A.: Role of green light in physiological activity of plants. - Russ. J. Plant Physiol. 62: 727-740, 2015

Govindjee (ed.): Photosynthesis: Energy Conversion by Plants and Bacteria. Vol. 1. Pp. 799. Academic Press, New York 1982a.

Govindjee (ed.): Photosynthesis: Development, Carbon Metabolism and Plant Productivity. Vol. 2. Pp. 580. Academic Press, New York 1982b.

Harley P.C., Loreto F., Di Marco G., Sharkey T.D.: Theoretical considerations when estimating the mesophyll conductance to $\mathrm{CO}_{2}$ flux by analysis of the response of photosynthesis to $\mathrm{CO}_{2}$. - Plant Physiol. 98: 1429-1436, 1992.

Hernández R., Kubota C.: Growth and morphological response of cucumber seedlings to supplemental red and blue photon flux ratios under varied solar daily light integrals. - Sci. Hortic.-Amsterdam 173: 92-99, 2014.

Hidaka K., Dan K., Imamura H. et al.: Effect of supplemental lighting from different light sources on growth and yield of strawberry. - Environ. Control Biol. 51: 41-47, 2013.

Hikosaka K., Terashima I.: A model of the acclimation of photosynthesis in the leaves of $\mathrm{C}_{3}$ plants to sun and shade with respect to nitrogen use. - Plant Cell Environ. 18: 605$618,1995$.

Hu W., Ren T., Meng F. et al.: Leaf photosynthetic capacity is regulated by the interaction of nitrogen and potassium through coordination of $\mathrm{CO}_{2}$ diffusion and carboxylation. - Physiol. Plantarum 167: 418-432, 2019.

Izzo L.G., Mele B.H., Vitale L. et al.: The role of monochromatic red and blue light in tomato early photomorphogenesis and photosynthetic traits. - Environ. Exp. Bot. 179: 104195, 2020.
Jahns P., Holzwarth A.R.: The role of the xanthophyll cycle and of lutein in photoprotection of photosystem II. BBA-Bioenergetics 1817: 182-193, 2012.

Jamal Uddin A.F.M., Hoq M.Y., Rini S.N. et al.: Influence of supplement LED spectrum on growth and yield of strawberry. - J. Biosci. Agric. Res. 16: 1348-1355, 2018.

Kalituho L., Rech J., Jahns P.: The roles of specific xanthophylls in light utilization. - Planta 225: 423-439, 2007.

Kim H.H., Goins G.D., Wheeler R.M., Sager J.C.: Green-light supplementation for enhanced lettuce growth under red- and blue-light emitting diodes. - HortScience 39: 1617-1622, 2004.

Kim K., Kook H.S., Jang Y.J. et al.: The effect of blue-light emitting diodes on antioxidant properties and resistance to Botrytis cinerea in tomato. - J. Plant Pathol. Microb. 4: 203, 2013.

Kitajima K., Hogan K.P.: Increases of chlorophyll $a / b$ ratios during acclimation of tropical woody seedlings to nitrogen limitation and high light. - Plant Cell Environ. 26: 857-865, 2003.

Landi M., Zivcak M., Sytar O. et al.: Plasticity of photosynthetic processes and the accumulation of secondary metabolites in plants in response to monochromatic light environments: A review. - BBA-Bioenergetics 1861: 148131, 2020.

Lee S.H., Tewari R.K., Hahn E.J., Paek K.Y.: Photon flux density and light quality induce changes in growth, stomatal development, photosynthesis and transpiration of Withania somnifera (L.) Dunal. plantlets. - Plant Cell Tiss. Org. Cult. 90: 141-151, 2007.

Lefsrud M.G., Kopsell D.A., Sams C.E.: Irradiance from distinct wavelenght light emmitting diodes affect secondary metabolites in kale. - HortScience 43: 2243-2244, 2008.

Leong T.Y., Anderson J.M.: Adaptation of the thylakoid membranes of pea chloroplasts to light intensities. I. Study on the distribution of chlorophyll-protein complexes. Photosynth. Res. 5: 105-115, 1984.

Li C.-X., Chang S.-X., Khalil-Ur-Rehman M. et al.: Effect of irradiating the leaf abaxial surface with supplemental lightemitting diode lights on grape photosynthesis. - Aust. J. Grape Wine Res. 23: 58-65, 2017.

Li H., Tang C., Xu Z. et al.: Effects of different light sources on the growth of non-heading Chinese cabbage (Brassica campestris L.). - J. Agr. Sci. 4: 262-273, 2012.

Li Q., Kubota C.: Effects of supplemental light quality on growth and phytochemicals of baby leaf lettuce. - Environ. Exp. Bot. 67: 59-64, 2009.

Li X.-P., Müller-Moulé P., Gilmore A.M., Niyogi K.K.: PsbSdependent enhancement of feedback de-excitation protects photosystem II from photoinhibition. - P. Natl. Acad. Sci. USA 99: 15222-15227, 2002.

Long S.P., Bernacchi C.J.: Gas exchange measurements, what can they tell us about the underlying limitations to photosynthesis? Procedures and sources of error. - J. Exp. Bot. 54: 2393-2401, 2003.

Loreto F., Tsonev T., Centritto M.: The impact of blue light on leaf mesophyll conductance. - J. Exp. Bot. 60: 2283-2290, 2009.

Matysiak B., Kowalski A.: White, blue and red LED lighting on growth, morphology and accumulation of flavonoid compounds in leafy greens. - Zemdirbyste 106: 281-286, 2019.

Mickens M.A., Torralba M., Robinson S.A. et al.: Growth of red pak choi under red and blue, supplemented white, and artificial sunlight provided by LEDs. - Sci. Hortic.-Amsterdam 245: 200-209, 2019.

Mizuno T., Amaki W., Watanabe H.: Effects of monochromatic 
light irradiation by LED on the growth and anthocyanin contents in leaves of cabbage seedlings. - Acta Hortic. 907: 179-184, 2011.

Momayyezi M., Guy R.D.: Blue light differentially represses mesophyll conductance in high vs low latitude genotypes of Populus trichocarpa Torr. \& Gray. - J. Plant Physiol. 213: 122-128, 2017.

Morrow R.C.: LED lighting in horticulture. - HortScience 43: 1947-1950, 2008.

Muneer S., Kim E.J., Park J.S., Lee J.H.: Influence of green, red and blue light emitting diodes on multiprotein complex proteins and photosynthetic activity under different light intensities in lettuce leaves (Lactuca sativa L.). - Int. J. Mol. Sci. 15: 4657-4670, 2014.

Munné-Bosch S., Alegre L.: The function of tocopherols and tocotrienols in plants. - Crit. Rev. Plant Sci. 21: 31-57, 2002.

Olle M., Virsile A.: The effects of light-emitting diode lighting on greenhouse plant growth and quality. - Agric. Food Sci. 22: 223-234, 2013.

Ouzounis T., Parjikolaei B.R., Fretté X. et al.: Predawn and high intensity application of supplemental blue light decreases the quantum yield of PSII and enhances the amount of phenolic acids, flavonoids, and pigments in Lactuca sativa. - Front. Plant Sci. 6: 19, 2015.

Peñuelas J., Baret F., Filella I.: Semi-empirical indices to assess carotenoids/chlorophyll a ratio from leaf spectral reflectance. - Photosynthetica 31: 221-230, 1995.

Qin X., Suga M., Kuang T., Shen J.R.: Structural basis for energy transfer pathways in the plant PSI-LHCI supercomplex. Science 348: 989-995, 2015.

Roberts M.R., Paul N.D.: Seduced by the dark side: integrating molecular and ecological perspectives on the influence of light on plant defence against pests and pathogens. - New Phytol. 170: 677-699, 2006.

Samuolienè G., Brazaityte A., Viršilè A. et al.: Red light-dose or wavelength-dependent photoresponse of antioxidants in herb microgreens. - PLoS ONE 11: e0163405, 2016.

Samuolienè G., Urbonavičiūtė A., Duchovskis P. et al.: Decrease in nitrate concentration in leafy vegetables under a solid-state illuminator. - HortScience 44: 1857-1860, 2009.

Silvestri C., Caceres M.E., Ceccarelli M. et al.: Influence of continuous spectrum light on morphological traits and leaf anatomy of hazelnut plantlets. - Front. Plant Sci. 10: 1318, 2019.

Singh D., Basu C., Meinhardt-Wollweber M., Roth B.: LEDs for energy efficient greenhouse lighting. - Renew. Sust. Energ. Rev. 49: 139-147, 2015.

Smith H.L., McAusland L., Murchie E.H.: Don't ignore the green light: exploring diverse roles in plant processes. J. Exp. Bot. 68: 2099-2110, 2017.

Solovchenko A.: Photoprotection in Plants: Optical ScreeningBased Mechanisms. Pp. 170. Springer, Berlin-Heidelberg 2010.

Su N., Wu Q., Shen Z. et al:: Effects of light quality on the chloroplastic ultrastructure and photosynthetic characteristics of cucumber seedlings. - Plant Growth Regul. 73: 227-235, 2014.

Sun J., Nishio J.N., Vogelmann T.C.: Green light drives $\mathrm{CO}_{2}$ fixation deep within leaves. - Plant Cell Physiol. 39: 10201026, 1998.

Sutherland M., Learmonth B.: The tetrazolium dyes MTS and XTT provide new quantitative assays for superoxide and superoxide dismutase. - Free Radic. Res. 27: 283-289, 1997.

Talbott L.D., Hammad J.W., Harn L.C. et al.: Reversal by green light of blue light-stimulated stomatal opening in intact, attached leaves of Arabidopsis operates only in the potassiumdependent, morning phase of movement. - Plant Cell Physiol. 47: 332-339, 2006.

Talbott L.D., Nikolova G., Ortiz A. et al.: Green light reversal of blue-light-stimulated stomatal opening is found in a diversity of plant species. - Am. J. Bot. 89: 366-368, 2002.

Terashima I., Hikosaka K.: Comparative ecophysiology of leaf and canopy photosynthesis. - Plant Cell Environ. 18: 1111$1128,1995$.

Thoma F., Somborn-Schulz A., Schlehuber D. et al.: Effects of light on secondary metabolites in selected leafy greens: A review. - Front. Plant Sci. 11: 497, 2020.

Viršilè A., Brazaitytė A., Vaštakaitė-Kairienè V. et al.: Nitrate, nitrite, protein, amino acid contents, and photosynthetic and growth characteristics of tatsoi cultivated under various photon flux densities and spectral light compositions. Sci. Hortic.-Amsterdam 258: 108781, 2019.

Viršilè A., Brazaitytė A., Jankauskienė J. et al.: Pre-harvest LED lighting strategies for reduced nitrate contents in leafy vegetables. - Zemdirbyste 105: 249-256, 2018.

Wang H., Gu M., Cui J. et al.: Effects of light quality on $\mathrm{CO}_{2}$ assimilation, chlorophyll-fluorescence quenching, expression of Calvin cycle genes and carbohydrate accumulation in Cucumis sativus. - J. Photoch. Photobio. B 96: 30-37, 2009.

Wang H., Jiang Y.P., Yu H.J. et al.: Light quality affects incidence of powdery mildew, expression of defence-related genes and associated metabolism in cucumber plants. - Eur. J. Plant Pathol. 127: 125-135, 2010.

Xu H., Fu Y.-N., Li T.-L., Wang R.: Effects of different LED light wavelengths on the resistance of tomato against Botrytis cinerea and the corresponding physiological mechanisms. J. Integr. Agr. 16: 106-114, 2017.

Young A.J.: Factors that affect the carotenoid composition of higher plants and algae. - In: Young A.J., Britton G. (ed.): Carotenoids in Photosynthesis. Pp. 160-205. Springer, Dordrecht 1993.

Zhou X., Huang W., Zhang J. et al.: A novel combined spectral index for estimating the ratio of carotenoid to chlorophyll content to monitor crop physiological and phenological status. - Int. J. Appl. Earth Obs. Geoinf. 76: 128-142, 2019.

Zukauskas A., Bliznikas Z., Breivė K. et al.: Effect of supplementary pre-harvest LED lighting on the antioxidant properties of lettuce cultivars. - Acta Hortic. 907: 87-90, 2011.

(C) The authors. This is an open access article distributed under the terms of the Creative Commons BY-NC-ND Licence. 